\title{
Oceanography
}

CITATION

Hogan, T.F., M. Liu, J.A. Ridout, M.S. Peng, T.R. Whitcomb, B.C. Ruston, C.A. Reynolds, S.D. Eckermann, J.R. Moskaitis, N.L. Baker, J.P. McCormack, K.C. Viner, J.G. McLay, M.K. Flatau, L. Xu, C. Chen, and S.W. Chang. 2014. The Navy Global Environmental Model.

Oceanography 27(3):116-125, http://dx.doi.org/10.5670/oceanog.2014.73.

$\mathrm{DOI}$

http://dx.doi.org/10.5670/oceanog.2014.73

COPYRIGHT

This article has been published in Oceanography, Volume 27, Number 3, a quarterly journal of The Oceanography Society. Copyright 2014 by The Oceanography Society. All rights reserved.

USAGE

Permission is granted to copy this article for use in teaching and research. Republication, systematic reproduction, or collective redistribution of any portion of this article by photocopy machine, reposting, or other means is permitted only with the approval of The Oceanography Society. Send all correspondence to: info@tos.org or The Oceanography Society, PO Box 1931, Rockville, MD 20849-1931, USA. 


\section{The Navy Global Environmental Model}
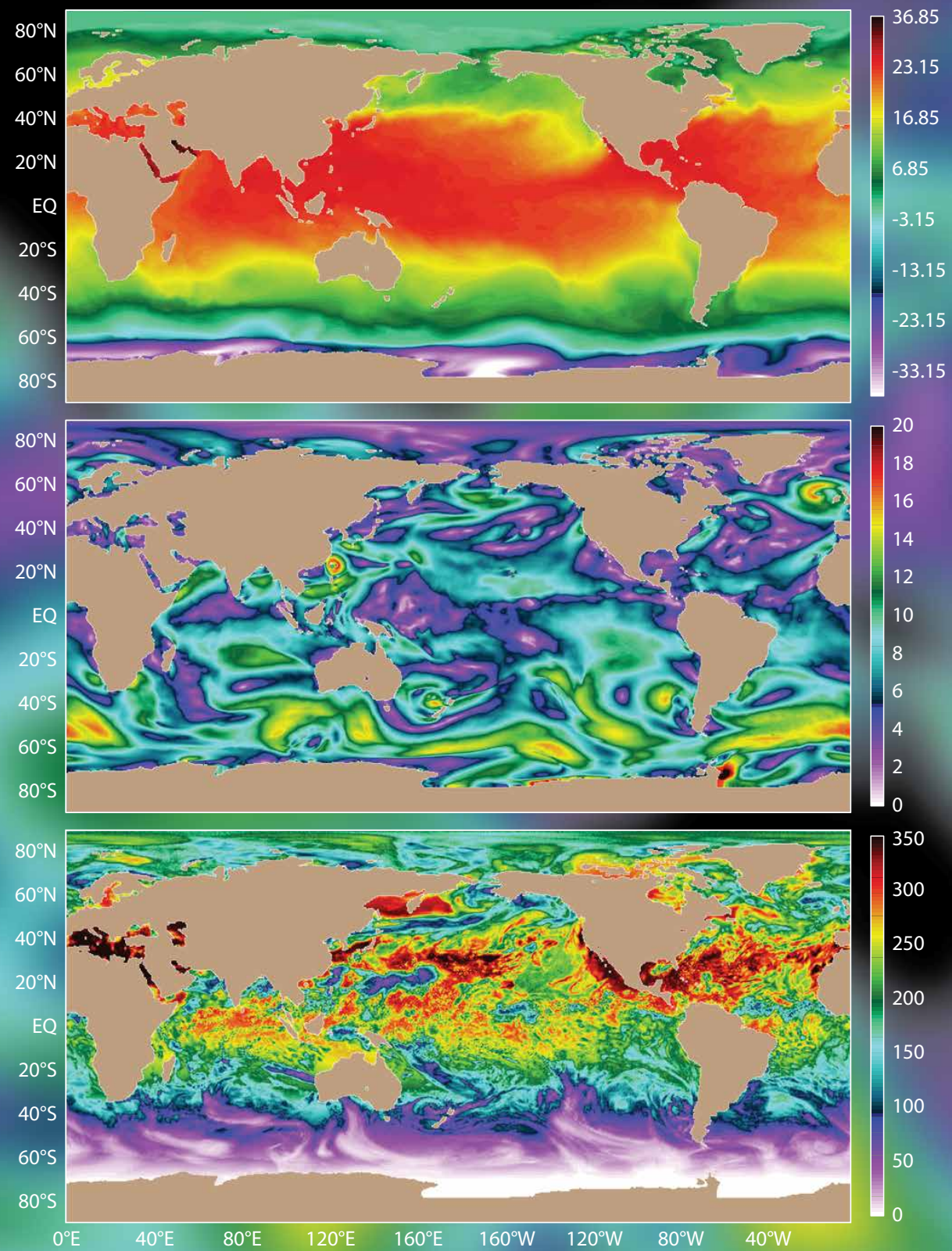

Figure 1. The August 12, 2012, average NAVy Global Environmental Model (NAVGEM) global fields of (a) $2 \mathrm{~m}$ surface air temperature over the ocean in degrees $C_{\text {, (b) }}$ the $10 \mathrm{~m}$ surface wind speed over the ocean in $\mathrm{m} \mathrm{sec}^{-1}$, and (c) downward solar radiation over the ocean in $\mathrm{W} \mathrm{m}^{-2}$.
BY TIMOTHY F. HOGAN, MING LIU,

JAMES A. RIDOUT, MELINDA S. PENG, TIMOTHY R. WHITCOMB, BENJAMIN C. RUSTON,

CAROLYN A. REYNOLDS, STEPHEN D. ECKERMANN, JON R. MOSKAITIS, NANCY L. BAKER, JOHN P. MCCORMACK, KEVIN C. VINER, JUSTIN G. MCLAY, MARIA K. FLATAU, LIANG XU, CHAING CHEN, AND SIMON W. CHANG 
ABSTRACT. On February 13, 2013, the US Navy's weather forecast system reached a milestone when the NAVy Global Environmental Model (NAVGEM) replaced the Navy Operational Global Atmospheric Prediction System (NOGAPS) for operational global weather prediction. The new operational system NAVGEM 1.1 combines a semi-Lagrangian/semi-implicit dynamical core together with advanced parameterizations of subgrid-scale moist processes, convection, ozone, and radiation. The NAVGEM dynamical core allows for much higher spatial resolutions without the need for the small time steps that would be necessary in NOGAPS. The increased computational efficiency is expected to enable significant increases in resolution in future NAVGEM releases. Model physics improvements in the NAVGEM 1.1 transition include representations of cloud liquid water, cloud ice water, and ozone as fully predicted constituents. Following successful testing of a new mass flux scheme, a second transition to NAVGEM 1.2 occurred on November 6, 2013. Addition of this mass flux parameterization to the eddy diffusion vertical mixing parameterization resulted in a reduction of the cold temperature bias of the lower troposphere over ocean and further increased the forecast skill of NAVGEM.

\section{INTRODUCTION}

The Navy's high-resolution global weather prediction system, run operationally at the Fleet Numerical Meteorology and Oceanography Center (FNMOC), is the critical component of the Navy's atmospheric prediction capabilities. The global model provides high-resolution 180-hour forecasts every six hours and twice-daily 16-day guidance using the 20 member global ensemble to numerous Navy and Marine Corps users. Approximately 150,000 global products are produced each day and are used as initial conditions, boundary conditions, and forcing for a large number of critical Department of Defense (DoD) environmental and application systems. Prominent among these applications are the Navy's Coupled Ocean-Atmosphere Mesoscale Prediction System (COAMPS ${ }^{\circledast}$ ), COAMPS-TC (the tropical cyclone prediction version of COAMPS), the Army's mesoscale Battlescale Forecast Model (BFM), the Navy Aerosol Analysis and Prediction System (NAAPS), the Navy's ocean wave model WAVEWATCH ${ }^{\circledR} \mathrm{III}$, the Navy's global HYbrid Coordinate
Ocean Model (HYCOM) and Arctic Cap Nowcast/Forecast System, the Navy's tropical cyclone forecast system Geophysical Fluid Dynamics laboratory Navy (GFDN) model, the Naval Observatory's effective atmospheric angular momentum functions (EAAMF) program, and the Navy's aircraft and ship-routing systems. For the ocean models, the principal products are the surface fields of pressure, winds, temperatures, drag, latent and sensible heat releases, and downward radiation fluxes. Figure 1 shows examples of three of the NAVy Global Environmental Model (NAVGEM) products used in ocean forecasting: the $2 \mathrm{~m}$ surface air temperature, the $10 \mathrm{~m}$ wind speed, and the downward shortwave radiation fields.

From August 1982 to February 2013, the Navy's global weather forecast model was the Navy Operational Global Atmospheric Prediction System (NOGAPS). While NOGAPS (Rosmond et al., 2002) underwent many resolution changes and improvements to parameterizations of subgrid-scale physical processes, its Eulerian spectral dynamical core prevented expansion beyond its final configuration of $42 \mathrm{~km}$ horizontal resolution and 42 vertical levels under operational computational constraints. An advanced semi-Lagrangian/ semi-implicit (SL/SI) dynamical core was developed by the Naval Research Laboratory (NRL) to address the need for increased global resolution together with more advanced physical parameterizations. The increased computational efficiency of using this new SL/SI formulation as the dynamical (adiabatic) core makes it computationally feasible to increase resolution, add more species, and improve physics. Thus, a new global SL/SI model-NAVGEM-was created.

For its initial configuration, NAVGEM 1.1 had $37 \mathrm{~km}$ horizontal resolution (spectral triangular truncation at wavenumber 359, i.e., T359) and 50 vertical levels, with ozone chemistry and prognostic representations of both cloud liquid water and cloud ice, as well as new cumulus, specific humidity, and radiation parameterizations. After extensive testing, NAVGEM 1.1 was officially transitioned to FNMOC, where an official operational test (OPTEST) of NAVGEM 1.1 versus NOGAPS was conducted for the period of November 6 , 2012, to December 18, 2012. FNMOC's global scorecard evaluates the comparative skills of the models based on $1,000 \mathrm{hPa}$ and $500 \mathrm{hPa}$ geopotential height anomaly correlation (AC), mean and root mean square errors of 16 different fields and observation types, including TC (tropical cyclone) tracks, 10 -meter winds at buoy sites, and winds and temperatures at radiosonde locations, assigning a weighted positive score to the model with statistically significant better forecasts. Improvements in all categories would yield a skill score of +24 . NAVGEM 1.1 scored $\mathrm{a}+14$, the highest score ever obtained for a global model 
transition at FNMOC. Historically, global model improvements resulted in a skill improvement of +2 . With these very positive results, NAVGEM 1.1 was transitioned as the Navy's operational global weather prediction model on February 13, 2013.

NRL plans regular upgrades to NAVGEM resolution physics. A new eddy diffusivity mass flux (EDMF) scheme (Sušelj et al., 2012, 2013) tested in NAVGEM as version 1.2 had overall in situ data from radiosondes, ships, and aircraft; radiances from infrared and microwave sounders; bending angles from Global Navigation Satellite System Radio Occultations; and winds derived from satellite scatterometers and tracked features. Because these components have been described elsewhere, in this paper we concentrate on describing the current configuration of the forecast component of NAVGEM 1.2 and briefly discuss future plans for the forecast model.

\section{CALCULATIONS IN SPECTRAL SPACE ARE PERFORMED FOR THE SI CORRECTIONS TO THE DIVERGENT COMPONENT OF THE WINDS, VIRTUAL POTENTIAL TEMPERATURE, AND SURFACE PRESSURE.}

positive results. An FNMOC OPTEST resulted in $\mathrm{a}+3$ on the scorecard. This version of NAVGEM 1.2 became operational on November 6, 2013.

For data assimilation, NAVGEM is coupled to the NRL Atmospheric Variational Data Assimilation System Accelerated Representer (NAVDAS-AR), which became operational in NOGAPS in 2009 (Xu et al., 2005; Rosmond and $\mathrm{Xu}, 2006$; Chua et al., 2009). However, in NAVGEM, the radiance bias correction method has been upgraded with a variational approach that estimates the bias predictors simultaneously with the atmospheric analysis during each data assimilation cycle (Dee, 2004). Every six hours, a NAVDAS-AR run for NAVGEM assimilates hundreds of data types and processes tens of millions of observations including: conventional

\section{OVERALL CONFIGURATION OF NAVGEM 1.2}

The forecast model uses both grid point and spectral (spherical harmonic) representations to perform the forecast. This combination is used to take advantage of the strengths of both formulations. Grid point calculations are performed for the SL advection and in all physical parameterizations. Calculations in spectral space are performed for the SI corrections to the divergent component of the winds, virtual potential temperature, and surface pressure. The advantage of this approach is that in spectral space the solutions to the SI and fourth order diffusion elliptic equations become simple algebraic equations. The disadvantage is the cost of the transform back and forth between grid point and spectral space.

The horizontal computational grid of NAVGEM 1.1 and 1.2 is a quadratic Gaussian grid of 1,080 x 540 grid points. This corresponds to T359 and a horizontal grid point resolution of $37 \mathrm{~km}$. The model has 50 vertical levels, with a model top of $0.04 \mathrm{hPa}$, which is approximately $70 \mathrm{~km}$ above sea level. The vertical coordinate is a hybrid pressure coordinate, which is terrain-following in the troposphere, then smoothly transitions to a pure pressure coordinate at $85 \mathrm{hPa}$, with 20 isobaric levels between $85 \mathrm{hPa}$ and $0.04 \mathrm{hPa}$ (Eckermann, 2009; Eckermann et al., 2014). As in NOGAPS, the time-differencing in NAVGEM is a three-time-level leap frog scheme. The atmospheric dynamical variables are surface pressure, east/west and north/south winds, virtual potential temperature, specific humidity, ozone, cloud liquid water, and cloud ice water. Spectral representations of vorticity and divergence are computed from the horizontal winds. The hydrostatic approximation (accurate down to $10 \mathrm{~km}$ horizontal resolutions) is assumed and used to calculate geopotential heights and vertical motion. Rain/snow rates are computed from the stratiform and cumulus parameterizations. For stratiform clouds, cloud fraction is computed based on the relative humidity, vertical motion, and lapse rate (Teixeira and Hogan, 2002), assuming cloud water is present; for cumulus clouds, the cloud fraction is computed based on the cumulus precipitation reaching the ground and the parameterized cloud base mass flux. In addition to the atmospheric variables, canopy temperature, ground temperature, ground liquid water, and ground ice water are computed down to a depth of $2 \mathrm{~m}$ (Hogan, 2007). The sea surface temperature (SST) and sea ice fractions are obtained from the FNMOC SST and sea ice analysis (Smith et al., 
2011) and are held fixed during the $180 \mathrm{~h}$ forecast. The sea ice temperature is computed based on the work of Winton (2000) with a fixed sea ice thickness of $1.5 \mathrm{~m}$. The time step is 360 seconds (three times the NOGAPS time step).

Virtually every physical parameterization from NOGAPS has been replaced or modified in NAVGEM 1.2. The suite includes orographic gravity-wave and flow-blocking drag (Webster et al., 2003), the EDMF vertical mixing (Louis et al., 1982; Sušelj et al., 2013), the Simplified Arakawa-Schubert cumulus parameterization (Moorthi et al., 2001), a shallow cumulus parameterization (Han and Pan, 2011), a convective cloud fraction parameterization based on a cloud base mass flux scaling modification of the Slingo (1987) scheme, a stratiform cloud fraction parameterization (Slingo, 1987; Teixeira and Hogan, 2002), a cloud water parameterization based on an extension of the scheme of Zhao and Carr (1997) to include prognostic representations of both cloud liquid and cloud ice, the Rapid Radiative Transfer Model for General Circulation Models (RRTMG) for solar and longwave radiation fluxes (Clough et al., 2005), a land surface parameterization (Hogan, 2007), and ozone photochemistry (McCormack et al., 2006). The coupling of the physics to the dynamical core is done in the same manner as in NOGAPS (Hogan et al., 1991). With the exception of radiation, which is called every two hours with radiation tendencies held fixed over that period, the parameterizations adjust (change) the winds, temperatures, moisture, ozone, and cloud water sequentially. Specifically, the gravity wave drag (GWD) adjusts the fields computed from the dynamical core with the radiation tendencies added in, the EDMF adjusts the fields from GWD calculations, the cumulus parameterization then adjusts these fields, and finally cloud physics, land surface, and ozone chemistry are the final adjustments for the next time step call to the dynamical core or radiation.

The following section briefly discusses the most significant changes in NAVGEM: the SL/SI, the cumulus parameterizations, the cloud water and ice microphysics, the RRTMG (Rapid Radiative Transfer Model for General Circulation Models), and the EDMF scheme.

\section{SEMI-LAGRANGIAN/SEMI-} IMPLICIT DYNAMICAL CORE The dynamical core of NAVGEM 1.2 is a three-time-level, SL/SI numerical integration of the hydrostatic equations of motion and the first law of thermodynamics. The dynamical variables are the east-west wind, the north-south wind, the virtual potential temperature, the specific humidity, the surface pressure, ozone, and cloud liquid and ice water. The SL/SI formulation is based on the work of Ritchie (1987, 1988, and 1991) and Ritchie et al. (1995) and is described in a European Centre for Mediumrange Weather Forecasts (ECMWF) documentation manual, (http://www. ecmwf.int/research/ifsdocs/CY36r1/ index.html). The major difference between the Ritchie and NAVGEM formulations is that NAVGEM uses potential temperature while ECMWF uses temperature. Potential temperature was used in NAVGEM to leverage the fact that NOGAPS used potential temperature as the dynamical variable and therefore the NOGAPS SI algorithm was applicable to NAVGEM.

The basic idea of any Lagrangian numerical technique is to find the trajectory of fluid motion that will end up at a particular location and to integrate the dynamical equations along this trajectory. For the SL technique, the trajectory is chosen such that it arrives at a model grid point at the valid forecast time, so the trajectory starts backwards in time either two time steps for a three-time-level scheme or one time step for a two-time-level scheme. The SL method removes the conventional Courant-Friedrichs-Lewy (CFL) limit on the time step for advection by the winds; however, because the primitive equations also allow high-speed gravity waves, the SL method must be merged with an implicit treatment of the gravity waves, which is conventionally called a semi-implicit (SI) method. Therefore, the three key components in the NAVGEM dynamical core are the calculation of the trajectory departure point, the interpolation of the terms in the SL equations,
Timothy F. Hogan (timothy.hogan@nrlmry.navy.mil), Ming Liu, James A. Ridout, Melinda S. Peng, Timothy R. Whitcomb, Benjamin C. Ruston, and Carolyn A. Reynolds are all meteorologists in the Marine Meteorology Division, Naval Research Laboratory (NRL), Monterey, CA, USA. Stephen D. Eckermann is a physicist in the Space Science Division, NRL, Washington, DC, USA. Jon R. Moskaitis and Nancy L. Baker are meteorologists in the Marine Meteorology Division, NRL, Monterey, CA, USA. John P. McCormack is a physicist in the Space Science Division, NRL, Washington, DC, USA. Kevin C. Viner, Justin G. McLay, Maria K. Flatau, and Liang Xu are all meteorologists in the Marine Meteorology Division, NRL, Monterey, CA, USA. Chaing Chen is a physicist with Science Applications International Corporation, Washington, DC, USA. Simon W. Chang is a meteorologist in the Marine Meteorology Division, NRL, Monterey, CA, USA. 
and the SI scheme.

The departure point is the position of the trajectory at an earlier time, given that it must arrive at the specified grid point at the current forecast time. This is a straightforward iterative calculation, made somewhat easier since the NAVGEM 1.2 SL algorithm is a threetime-level scheme and the velocities at the previous time step are known. Because the departure point will usually never be located on a grid point, three iterations are performed using linear interpolation to locate the mid-point of the trajectory, and the departure point is then given by a trajectory integrated back to the time. A slight final adjustment is made to ensure that the departure point corresponds to a point with a central radius given by Earth's radius (Ritchie 1987).

Once the departure point is calculated, the dynamical (adiabatic) equations for $\mathrm{u}, \mathrm{v}$, virtual potential temperature, specific humidity, surface pressure, ozone, and cloud water are integrated in time along this trajectory. This requires the interpolation of terms at the departure point and the mid-point at times $\mathrm{t}-2 \Delta \mathrm{t}$ and $\mathrm{t}-\Delta \mathrm{t}$, respectively. For the advection of tracers, such as ozone, the field (mixing ratio) is conserved along the trajectory, so that the integration along the trajectory yields

$\mathrm{q}\left(\lambda_{\mathrm{a}}, \varphi_{\mathrm{a}}, \eta_{\mathrm{a}}, \mathrm{t}\right)=\mathrm{q}\left(\lambda_{\mathrm{d}}, \varphi_{\mathrm{d}}, \eta_{\mathrm{d}}, \mathrm{t}-2 \Delta \mathrm{t}\right)$,

where $\left(\lambda_{\mathrm{a}}, \varphi_{\mathrm{a}}, \eta_{\mathrm{a}}\right)$ is the arrival point (a model grid point), and $\left(\lambda_{\mathrm{d}}, \varphi_{\mathrm{d}}, \eta_{\mathrm{d}}\right)$ is the departure point. For Equation 1, the term on the right side is obtained by a three-dimensional interpolation using cubic polynomials in the horizontal and a cubic interpolation in the vertical except for potential temperature. For virtual potential temperature, a weighted linear/cubic interpolation is used for pressures less than $200 \mathrm{hPa}$ where the vertical interpolation is $75 \%$ cubic interpolation plus $25 \%$ linear interpolation. This weighted interpolation, employed to reduce a stratospheric cold bias seen in the full cubic interpolation, will be fixed in future transitions to NAVGEM. Full cubic interpolation requires 64 points, but linear interpolation can be used on the edges of the box, which reduces the interpolation to 32 points. Because message passing and interpolation are the most expensive part of the SL calculation, this reduced number of points requiring interpolation has the positive effect of reducing the total wall clock time by $25 \%$, with the current eight three-dimensional SL variables.

The calculations of the non-tracer-like terms are more complicated. For winds, pressure derivatives and Coriolis terms must be evaluated at time $\mathrm{t}-\Delta \mathrm{t}$ and virtual potential temperature terms are needed for the SI calculations; for virtual potential temperature, there are vertical motion terms for the SI (Hogan et al., 1991); and for surface pressure, there are vertical advection and SI divergence terms. To reduce the computational cost of the SL calculations, terms computed at the mid-point are given by the average of the values at the departure point and the arrival point:

$$
\begin{gathered}
\psi\left(\lambda_{\mathrm{m}}, \varphi_{\mathrm{m}}, \eta_{\mathrm{m}}, \mathrm{t}-\Delta \mathrm{t}\right)= \\
\left(\frac{\psi\left(\lambda_{\mathrm{a}}, \varphi_{\mathrm{a}}, \eta_{\mathrm{a}}, \mathrm{t}-\Delta \mathrm{t}\right)+\psi\left(\lambda_{\mathrm{d}}, \varphi_{\mathrm{d}}, \eta_{\mathrm{d}}, \mathrm{t}-\Delta \mathrm{t}\right)}{2}\right)
\end{gathered}
$$

where $\left(\lambda_{\mathrm{m}}, \varphi_{\mathrm{m}}, \eta_{\mathrm{m}}\right)$ denotes the mid-point of the trajectory. Using Equation 2 significantly reduces the cost of the three-time-level SL calculations, effectively making the three-time level as efficient as the two-time level for the same time step. In future NAVGEM transitions, a two-time-level scheme will replace the three-time-level scheme, enabling higher time steps. Following Ritchie (1988), the horizontal wind equations are integrated using the vector form of the momentum equation. Because the result of this integration transforms the winds off the spherical grid, a transformation of the winds back to the spherical grid is required after the SL integration. Finally, it was found that the standard NAVGEM SL integration of the surface pressure, denoted as $\pi$, led to large height errors over regions with steep terrain, especially Antarctica. Therefore, following ECMWF, the SL integration for surface pressure uses the modified variable $\pi^{*}$, defined as

$\pi^{\star}=\pi+\left(p_{S} g / R T_{S}\right) z_{s}(\lambda, \varphi)$,

where $z_{s}$ is the terrain height, $p_{S}$ is a constant standard surface pressure of $1,000 \mathrm{hPa}, g$ is the gravitational acceleration, $R$ is the gas constant, and $T_{S}$ is a constant surface temperature of $300 \mathrm{~K}$.

The SL method alone treats only the explicit advection of the fields by the winds. The primitive equations support the propagation of high speed gravity waves, which must be handled in an implicit manner (slowing down any waves that are temporally unresolved) to permit a larger time step. Robert et al. (1972) pioneered this mathematical method. The procedure in NAVGEM, which leads to corrections for the potential temperature, winds, and surface pressure, is the same as the NOGAPS algorithm (Hogan et al., 1991). The SI is off-centered forward with a weight of $80 \%$ toward the forward variables. Finally, because the time integration scheme is three-time level, a Robert-time filter (Robert, 1981), with a coefficient of 0.05 , is applied to all forecast fields (after the diabatic adjustments from the parameterizations are added) to suppress computational modes. 
PARAMETERIZATIONS OF

PHYSICAL PROCESSES

Cumulus Convection Scheme

The NAVGEM 1.2 physical parameterization suite includes the Simplified Arakawa-Schubert (SAS) cumulus parameterization scheme and the National Centers for Environmental Prediction (NCEP) Global Forecast System's shallow cumulus (GFS/SC) parameterization (Han and Pan, 2011). These parameterizations take the place of the Emanuel cumulus scheme (Peng et al., 2004) used in NOGAPS. In SAS, convection is assumed to occur when the cloud work function is greater than a given climatological cloud work function value. The cloud base cumulus mass flux is determined from the difference between the cloud work function and an assumed climatological value, and depends on the stabilization rate computed for a test mass flux. The temperature, moisture, and rainfall are computed based on temperature and moisture budget equations consistent with specified entrainment and detrainment rates. A simplification that the SAS scheme makes is that there is just one cloud type (the deepest allowable) as opposed to a spectrum of clouds. Cumulus convection is assumed to occur only if an air parcel lifted from the level of maximum moist static energy can reach its level of free convection within a specified range of $120-180 \mathrm{hPa}$, depending on the large-scale vertical velocity. SAS also has a sophisticated cumulus momentum transport scheme that includes the effects of the cumulus-induced pressure gradient force.

Following the calculations of the deep convection, the GFS/SC parameterization, developed to be run in conjunction with SAS, is called. Like SAS, the GFS/ $\mathrm{SC}$ scheme is a mass-flux scheme together with a cloud budget model based on specified entrainment and detrainment rates to describe induced changes in temperature and moisture. The scheme includes a parameterized representation of precipitation processes as well as a treatment of convective momentum transport. The cloud-base mass flux in this scheme is computed as a fraction of the convective turbulent latent heat energy.

Zhao and Carr (1997) developed the original GFS scheme (see also Sundqvist et al., 1989, and Moorthi et al., 2001). It includes parameterized representations of major cloud phase transformation processes. A Sundqvist et al. (1989) condensation scheme is used to constrain the rate of condensation, enabling a representation of partial

THE NAVGEM 1.2 PHYSICAL PARAMETERIZATION SUITE INCLUDES THE SIMPLIFIED ARAKAWA-SCHUBERT (SAS) CUMULUS PARAMETERIZATION SCHEME AND THE NATIONAL CENTERS FOR ENVIRONMENTAL PREDICTION (NCEP) GLOBAL FORECAST SYSTEM'S SHALLOW CUMULUS (GFS/SC) PARAMETERIZATION.

velocity scale, which is a function of the planetary boundary layer (PBL) height and the surface buoyancy flux. As with SAS, GFS/SC uses the level of free convection as the cloud base. The cloud top maximum in the scheme is limited to pressures that are within $30 \%$ of the surface pressure.

\section{Cloud Water and Ice}

Parameterizations

The prognostic representation of cloud water and ice in NAVGEM 1.2 is accomplished through a two-species extension of the single bulk cloud water variable scheme in the NCEP GFS (which is itself implemented in NAVGEM as one of the cloud options). The NAVGEM 1.2 two-species treatment provides for improved conservation of cloudiness and helping to maintain cloud dynamics in balance with the environment. Partitioning of condensate between cloud water and precipitation is based on treatments by both Zhao and Carr (1997) and Sundqvist et al. (1989). Precipitation is assumed to fall to the ground immediately, resulting in high efficiency for NWP applications.

The NAVGEM 1.2 two-species scheme is in many ways a simple extension of the GFS cloud scheme, including most aspects of the parameterized cloud phase transformation processes and precipitation fallout. There are also some key differences between the schemes. For example, both schemes implement an assumed temperature-dependent partitioning between cloud water and ice. In the two-species scheme, differences 
between the parameterized partitioning at each time step and the prognostic cloud liquid and ice mixing ratios result in latent heat exchanges to adjust toward the parameterized partitioning (in this case an assumed linear transition between liquid and ice). The treatments of both condensation and evaporation in the NAVGEM 1.2 two-species cloud scheme also include some unique features. The relative humidity threshold for condensation is specified to vary with cloud cover. This treatment was adopted because the cloud cover scheme in NAVGEM 1.2 differs from that specified within the condensation scheme and is designed to provide a greater degree of consistency between condensation and cloud cover in the model. As in the GFS scheme, precipitation is removed from the vertical column instantaneously. In contrast to the GFS scheme, evaporation of cloud water is assumed to occur at a finite rate rather than instantaneously. In the case of convective clouds, the assumed rate varies with cloud cover. This treatment improves predicted distribution of cloud water in major convective regions based on comparisons with the Tropical Rainfall Measuring Mission (TRMM; e.g., Simpson et al., 1988; Schumacher and Houze, 2000) cloud liquid water retrievals. This feature of the scheme is further enhanced in NAVGEM 1.2 by enabling the detrainment of cloud condensate between the lifting condensation level and the level of free convection.

\section{The NAVGEM Radiation}

\section{Parameterization}

The advanced radiation parameterization RRTMG, developed by Atmospheric Environmental Research Inc., has been implemented into NAVGEM 1.2. It parameterizes absorption and two-stream scattering in 14 spectral bands from 820 to $50,000 \mathrm{~cm}^{-1}$ in shortwave radiation, and longwave radiation in 16 spectral bands from 10 to $3,250 \mathrm{~cm}^{-1}$. It utilizes the correlated-k approach to calculate radiative fluxes and heating rates efficiently and accurately. Absorption coefficient data for k-distributions are obtained from a detailed line-by-line radiative transfer model, which has been extensively validated against observations. Computational efficiency is achieved through a $50 \%$ reduction in pseudo-spectral intervals for integrating absorption and extinction in each waveband relative to full set of the intervals in RRTM. Modeled molecular absorbers and sources of extinction are water vapor, carbon dioxide, ozone, nitrous oxide, methane, oxygen, nitrogen, aerosols, several halocarbons, and Rayleigh scattering. It includes a McICA (Monte-Carlo Independent Column Approximation) capability to represent subgrid cloud variability with random, maximum random, and maximum options for cloud overlap. The optical properties of water and ice clouds are parameterized for each spectral band as functions of cloud equivalent radius and cloud mass contents. RRTMG also calculates the radiative effects of aerosol absorption and scattering upon provision of the aerosol optical properties. The radiative fluxes calculated by RRTMG agree with those computed by the line-by-line radiation model within $1.0 \mathrm{~W} \mathrm{~m}^{-2}$ at all levels, and the computed cooling rates generally agree to within $0.1 \mathrm{~K}$ per day in the troposphere and $0.3 \mathrm{~K}$ per day in the stratosphere. For further information on RRTMG and its implementation in other systems, see Clough et al. (2005), Pincus et al. (2003), Morcrette (2001), Iacono et al. (2000), and Mlawer et al. (1997).
The NAVGEM Eddy Diffusion/ Mass Flux Parameterization

As part of the turbulent mixing parameterizations, a mass flux calculation has been added to NAVGEM as part of the NAVGEM 1.2 transition. The total non-precipitating vertical turbulent flux is parameterized as

$w^{\prime} \varphi^{\prime}=-K \frac{\partial \varphi}{\partial z}+\sum_{i=1}^{N_{\text {updates }}} M_{i}\left(\varphi_{i}^{u p}-\varphi\right)$,

where $w$ is the vertical velocity; $\varphi$ represents virtual potential temperature, specific humidity, or the horizontal winds, which is the weighted sum of the updraft and downdraft regions; $M_{i}=a_{u p} w_{u p}$ is the upward mass flux of a given updraft ( $a_{u p}$ is the fractional area of the updraft set at $7 \%$ and $w_{u p}$ is the upward vertical velocity in the updraft region); and $\varphi_{i}^{u p}$ represents the variable in the updraft region. The first term on the right represents the local mixing by eddy diffusion (ED), which NAVGEM parameterizes using a Louis-type scheme (Louis et al., 1982). The second term is the mass flux (MF) contribution due to turbulent updrafts (non-local change) in the PBL, parameterized using the method of Sušelj et al. (2012). The vertical MF profiles are computed from the turbulent kinetic energy budget equation (change of kinetic energy $w_{u p}^{2} / 2$ is the difference of buoyance and turbulent energy dissipation) and an equation for the entraining/detraining of wind, potential temperature, and moisture in the vertical due to entrainment and detrainment to calculate $\varphi_{i}^{u p}$. The mass flux starts from a positive buoyancy flux as a single dry updraft, which is then split into 10 saturated updrafts. The entrainment of these saturated updrafts is computed using a random number from a Poisson distribution to give a wide range of possible heating 
profiles in the PBL. The overall effect in NAVGEM 1.2 has been to reduce the cold bias in the lower levels over ocean and to further increase prediction skill as measured by geopotential height root mean square error and anomaly correlations.

\section{NAVGEM VS. NOGAPS}

\section{VERIFICATION}

The NAVGEM 1.1 (horizontal resolution of $37 \mathrm{~km}$ ) with data assimilation and forecasts out to 120 hours was run over both summer and winter seasons, and the results were compared to the operational NOGAPS (42 km resolution) forecasts over the same period. As measured by standard verification statistics, the accuracy of NAVGEM's forecasts show significant improvements over NOGAPS's forecasts. Figure 2 shows the Northern Hemisphere (NH) $500 \mathrm{hPa}$ geopotential height anomaly correlations (AC) for the 2012 summer period of July 1, 2012-October 31, 2012, and Figure 3 is the $500 \mathrm{hPa}$ height $\mathrm{AC}$ for the fall/winter period of December 1, 2012-February 12, 2013 (NAVGEM 1.1 went operational on February 13, 2013). The AC, a fundamental metric used by all major NWP centers, is the normalized correlation of the forecast and analysis differences with climatology, with 1.0 being a perfect forecast. From this and other $(1,000 \mathrm{hPa} \mathrm{AC}$ and radiosonde) verification scores, it is concluded that NAVGEM 120-hour NH forecasts show a six hour improvement over the NOGAPS forecasts for the 2012 summer period and a three hour improvement in the 2012/2013 winter period. Similar results are found for the Southern Hemisphere $500 \mathrm{hPa}$ height AC (not shown).

Tropical cyclone (TC) track forecasts are of vital importance to the safety of
US Navy ships, aircraft, and personnel. Figure 4 shows the TC track error comparison in nautical miles (nmi) for summer/fall 2012. The NAVGEM TC track error is $30 \mathrm{~nm}$ less than NOGAPS at forecast days 4 and 5, approximately a 12-hour improvement.

Synoptic evaluations of daily weather maps show reduced surface pressure errors with NAVGEM, particularly for maritime lows that impact the safety of ships at sea. In addition, the mid-level troughs associated with frontal systems were generally more realistic (deeper and faster moving) in NAVGEM than in NOGAPS.

Following successful implementation and testing of the new mass flux (MF) scheme, NAVGEM 1.2 was transitioned on November 6, 2013. The addition of the MF parameterization to the eddy diffusion (ED) vertical mixing parameterization resulted in reduction of the lower tropospheric cold temperature bias over ocean and an increase in the forecast skill of four hours as measured by the $500 \mathrm{hPa}$ height AC (not shown).

\section{FUTURE NAVGEM UPGRADES}

Current work toward future NAVGEM upgrades is focused on increasing horizontal and vertical resolution. While the SL/SI dynamical core allows circumvention of the strict CFL link between time step and spatial resolution, higher resolution forecasts with strict operational time limits pose challenges for ensuring computational efficiency.
NOGAPS/NAVGEM Forecast Model Test 500 MB North Hem Height Anomaly Cor $2012070100-2012103100$

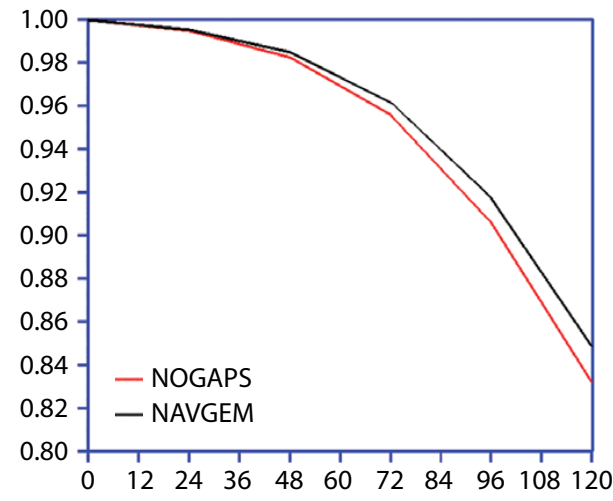

NOGAPS/NAVGEM Forecast Model Test 500 MB North Hem Height Anomaly Cor $2012120100-2013021200$

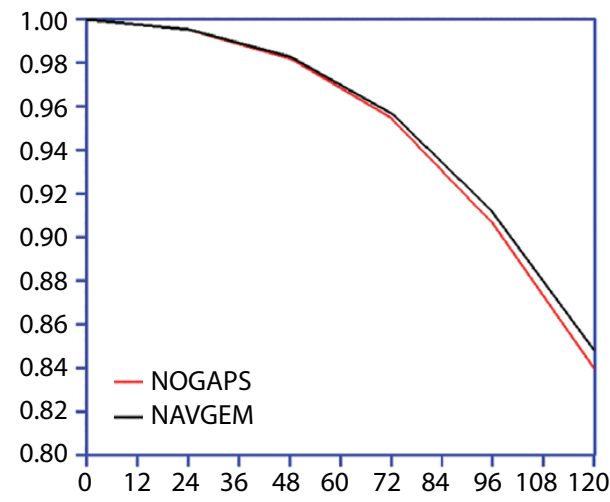

Figure 2. The $500 \mathrm{hPa}$ height anomaly correlations scores for the Navy Operational Global Atmospheric Prediction System (NOGAPS) and for NAVGEM for the forecast period of July 1 , 2012-September 30, 2012.
Figure 3. The $500 \mathrm{hPa}$ height anomaly correlations scores for NOGAPS and NAVGEM for the forecast period of December 1 , 2012-February 12, 2013. 
TROPICAL STORM TRACKER ERROR

July 1, 2012-October 31, 2012

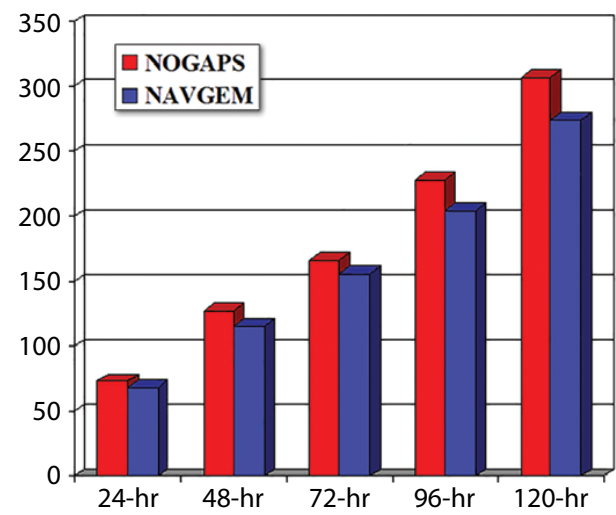

Figure 4. The tropical

cyclone track errors in nautical miles for NOGAPS and NAVGEM for the period of July 1, 2012-October 31, 2012. At 120 hours there were 132 tropical storms that verified.
Testing is underway using a reduced Gaussian grid (which reduces the number of grid points nearer to the pole; e.g., Hortal and Simmons, 1991) as well as a linear Gaussian grid (which allows for higher spectral truncation while leaving grid point resolution unchanged) and methods for improved accuracy in the spherical harmonic transforms.

A modification to the SL/SI dynamics to use perturbation virtual potential temperature as a prognostic variable has been developed to ensure greater numerical stability through improved handling of fast waves. This new method may allow higher time steps for a given spatial resolution, and assessment of the impact on forecast skill is ongoing. In addition, work is being pursued on a two-timelevel version of the SL/Si dynamical core. Numerous updates to the various physical parameterizations (particularly cloud processes) are in development, and future NAVGEM versions will include parameterizations targeting improvements in the stratosphere, which is important for making better use of satellite observations. These new parameterizations include non-orographic gravity wave drag (Eckermann, 2011) and new treatments of water vapor and ozone photochemistry (e.g., McCormack et al., 2008). NAVGEM is also being developed as one component of a fully coupled atmosphere-ocean-ice system targeting extended-range Earth system prediction. In addition to infrastructure modifications to enable coupling, ongoing work aims to improve the parameterization of surface fluxes and to ensure their consistency between coupled components. The transition from NOGAPS to NAVGEM represents a significant step forward for the Navy's numerical weather prediction program. With this foundation, future upgrades will further ensure decision superiority for both military and civilian customers.

\section{ACKNOWLEDGEMENTS}

We acknowledge the support of the Office of Naval Research's Program Element (PE) 0602435N and PMW-120 PE 0603207N. We also appreciate support for computational resources through a grant of Department of Defense High Performance Computing time from the DoD Supercomputing Resource Center at Stennis, MS. Thanks to Jan Dastugue for providing the plot of Figure 1. This is NRL contribution NRL/SP/7530-14-025, which is approved for public release and distribution is unlimited.

\section{REFERENCES}

Chua, B., L. Xu, T. Rosmond, and E. Zaron. 2009. Preconditioning representer-based variational data assimilation systems: Application to NAVDAS-AR. Pp. 307-320 in Data Assimilation for Atmospheric, Oceanic and Hydrologic Applications. Springer-Verlag, http://dx.doi.org/ 10.1007/978-3-540-71056-1_16.

Clough, S.A., M.W. Shephard, E.J. Mlawer, J.S. Delamere, M.J. Iacono, K. Cady-Pereira, S. Boukabara, and P.D. Brown. 2005. Atmospheric radiative transfer modeling: A summary of the AER codes: Short communication. Journal of Quantitative Spectroscopy and Radiative Transfer 91:233-244.

Dee, D. 2004. Variational bias correction of radiance data in the ECMWF system. Pp. 97-112 in Proceedings of the ECMWF Workshop on Assimilation of High Spectral Resolution Sounders in NWP. June 28-July 1, 2004, European Centre for Medium-range Weather Forecasts (ECMWF), Reading, UK.

Eckermann, S.D. 2009. Hybrid $\sigma$-p coordinate choices for a global model. Monthly Weather Review 137:224-245, http://dx.doi.org/ 10.1175/2008MWR2537.1.

Eckermann, S.D. 2011. Explicitly stochastic parameterization of nonorographic gravity-wave drag. Journal of the Atmospheric Sciences 68:1,749-1,765, http://dx.doi.org/ 10.1175/2011JAS3684.1.

Eckermann, S.D., J.P. McCormack, J. Ma, T.F. Hogan, and K.A. Zawdie. 2014. Stratospheric analysis and forecast errors using hybrid and sigma coordinates. Monthly Weather Review 142:476-485, http://dx.doi.org/10.1175/ MWR-D-13-00203.1.

Han, J., and H.-L. Pan. 2011. Revision of convection and vertical diffusion schemes in the NCEP Global Forecast System. Weather and Forecasting 26:520-533, http://dx.doi.org/ 10.1175/WAF-D-10-05038.1.

Hogan, T.F. 2007. Land surface modeling in the Navy Operational Global Atmospheric Prediction System. Paper presented at AMS 22nd Conference on Weather Analysis and Forecasting/189th Conference on Numerical Weather Prediction, June 2007, Park City, Utah. Extended abstract and recorded presentation available online at: https://ams. confex.com/ams/22WAF18NWP/techprogram/ paper_123403.htm (accessed May 12, 2014).

Hogan, T.F., T.E. Rosmond, and R. Gelaro. 1991. The NOGAPS Forecast Manual: A Technical Description. NOARL Technical Report 13, December 1991, 220 pp.

Hortal, M., and A.J. Simmons. 1991. Use of reduced Gaussian grids in spectral models. Monthly Weather Review 119:1,057-1,074, http://dx.doi.org/10.1175/1520-0493(1991)119 $<1057$ :UORGGI $>2.0$. .CO;2.

Iacono, M.J., E.J. Mlawer, S.A. Clough, and J.-J. Morcrette. 2000. Impact of an improved longwave radiation model, RRTM, on the energy budget and thermodynamic 
properties of the NCAR community climate mode, CCM3. Journal of Geophysical Research 105:14,873-14,890, http://dx.doi.org/ 10.1029/2000JD900091.

Louis, J.F., M. Tiedtke, and J.F. Geleyn. 1982. A short history of the operational PBL parameterization at ECMWF. Pp. 59-79 in ECMWF Workshop on Planetary Boundary Parameterizations. European Centre for Medium-range Weather Forecasts.

McCormack, J.P., S.D. Eckermann, D.E. Siskind, and T.E. McGee. 2006. CHEM2D-OPP: A new linearized gas-phase ozone photochemistry parameterization for high-altitude NWP and climate models. Atmospheric Chemistry and Physics 6:4,943-4,972, http://dx.doi.org/ 10.5194/acp-6-4943-2006.

McCormack, J.P., K.W. Hoppel, and D.E. Siskind. 2008. Parameterization of middle atmospheric water vapor photochemistry for high-altitude NWP and data assimilation. Atmospheric Chemistry and Physics 8:7,519-7,532, http://dx.doi.org/10.5194/acp-8-7519-2008.

Mlawer, E.J., S.J. Taubman, P.D. Brown, M.J. Iacono, and S.A. Clough. 1997. Radiative transfer for inhomogeneous atmospheres: RRTM, a validated correlated- $\mathrm{k}$ model for the longwave. Journal of Geophysical Research 102:16,663-16,682, http://dx.doi.org/ 10.1029/97JD00237.

Morcrette, J.-J. 2001. Impact of the radiationtransfer scheme RRTM in the ECMWF forecasting system. ECMWF [European Centre for Medium-range Weather Forecasts] Newsletter No. 91.

Moorthi, S., H.-L. Pan, and P. Caplan. 2001. Changes to the 2001 NCEP operational MRF/ AVN global analysis/forecast system. NWS Technical Procedures Bulletin, Series 484. 14 pp. Available at http://www.nws.noaa.gov/om/ tpb/484.htm.

Peng, M.S., J.A. Ridout, and T.F. Hogan. 2004. Recent modifications of the Emanuel Convective Scheme in the Navy Operational Global Atmospheric Prediction System. Monthly Weather Review 132:1,254-1,268, http://dx.doi.org/10.1175/1520-0493(2004)132 $<1254$ :RMOTEC $>2.0 . C O ; 2$.

Pincus, R., H.W. Barker, and J.-J. Morcrette. 2003. A fast, flexible, approximate technique for computing radiative transfer in inhomogeneous clouds. Journal of Geophysical Research 108, 4376, http://dx.doi.org/10.1029/2002JD003322.

Ritchie, H. 1987. Semi-Lagrangian advection on a Gaussian grid. Monthly Weather Review 115:608-619, http://dx.doi.org/10.1175/ 1520-0493(1987)115<0608:SLAOAG>2.0.CO;2.

Ritchie, H. 1988. Application of the semiLagrangian method to a spectral model of the shallow water equations. Monthly Weather Review 116:1,587-1,598, http://dx.doi.org/ 10.1175/1520-0493(1988)116<1587: AOTSLM>2.0.CO;2.
Ritchie, H. 1991. Application of the semiLagrangian method to a multilevel spectral primitive equation model. Quarterly Journal of the Royal Meteorological Society 117:91-106, http://dx.doi.org/10.1002/qj.49711749705.

Ritchie, H., C. Temperaton, A. Simmons, M. Hortal, T. Davies, D. Dent, and M. Hamrud. 1995. Implementation of the semi-Lagrangian method in a high-resolution version of the ECMWF forecast model. Monthly Weather Review 123:489-514, http://dx.doi.org/10.1175/ 1520-0493(1995)123<0489:IOTSLM>2.0.CO;2.

Robert, A.J. 1981. A stable numerical integration scheme for the primitive meteorological equations. Atmosphere-Ocean 19:35-46, http://dx.doi.org/10.1080/07055900.1981. 9649098.

Robert, A.J., H. Henderson, and C. Turbull. 1972. An implicit time integration scheme for baroclinic models of the atmosphere. Monthly Weather Review 100:329-335, http://dx.doi.org/10.1175/1520-0493(1972) 100<0329:AITISF>2.3.CO;2.

Rosmond, T.E., J. Teixeira, M. Peng, T.F. Hogan, and R. Pauley. 2002. Navy Operational Global Atmospheric Prediction System (NOGAPS): Forcing for ocean models. Oceanography 15(1):99-108, http://dx.doi.org/ 10.5670/oceanog.2002.40.

Rosmond, T., and L. Xu. 2006. Development of NAVDAS-AR: Non-linear formulation and outer loop tests. Tellus 58A:45-58, http://dx.doi.org/ 10.1111/j.1600-0870.2006.00148.x.

Schumacher, C., and R.A. Houze Jr. 2000. Comparison of radar data from the TRMM satellite and Kwajalein oceanic validation site. Journal of Applied Meteorology 39:2,151-2,164, http://dx.doi.org/10.1175/1520-0450(2001)040 $<2151$ :CORDFT $>2.0$. CO;2.

Simpson, J., R.F. Adler, and G.R. North. 1988. A proposed Tropical Rainfall Measuring Mission (TRMM) satellite. Bulletin of the American Meteorological Society 69:278-295, http://dx.doi.org/10.1175/1520-0477(1988) 069<0278:APTRMM >2.0.CO;2.

Slingo, J. 1987. The development and verification of a cloud prediction scheme for the ECMWF model. Quarterly Journal of the Royal Meteorological Society 113:899-927, http://dx.doi.org/10.1002/qj.49711347710.

Smith, S., J.A. Cummings, C. Rowley, P. Chu, J. Shriver, R. Helber, P. Spence, S. Carroll, and O.M. Smedstad. 2011. Validation Test Report for the Navy Coupled Ocean Data Assimilation $3 D$ Variational Analysis (NCODA-VAR) System, Version 3.43. NRL Report NRL/MR/7320-119363. Naval Research Laboratory, Stennis Space Center, MS.

Sundqvist, H., E. Berge, and J.E. Kristjansson. 1989. Condensation and cloud paramaterization studies with mesoscale numerical weather prediction model. Monthly Weather Review 117:1,641-1,757, http://dx.doi.org/10.1175/1520-0493(1989) 117<1641:CACPSW >2.0.CO;2
Sušelj, K., J. Teixeira, and D. Chung. 2013. A unified model for moist convective boundary layers based on a stochastic eddy-diffusivity/ mass-flux parameterization. Journal of the Atmospheric Sciences 70:1,929-1,953, http://dx.doi.org/10.1175/JAS-D-12-0106.1.

Sušelj, K., J. Teixeira, and G. Matheou. 2012. Eddy diffusivity/mass flux and shallow cumulus boundary layer: An updraft PDF multiple mass flux scheme. Journal of Atmospheric Sciences 69:1,513-1,533, http://dx.doi.org/ 10.1175/JAS-D-11-090.1.

Teixeira, J., and T.F. Hogan. 2002. Boundary layer clouds in a global atmospheric model: Simple cloud cover parameterizations. Journal of Climate 15:1,261-1,276, http://dx.doi.org/10.1175/1520-0442(2002) 015<1261:BLCIAG >2.0.CO;2.

Webster, S., A.R. Brown, D.R. Cameron, and C.P. Jones. 2003. Improvements to the representation of orography in the Met Office Unified Model. Quarterly Journal of the Royal Meteorological Society 133:1,989-2,010, http://dx.doi.org/10.1256/qj.02.133.

Winton, M. 2000. A reformulated three-layer sea ice model. Journal of Atmospheric and Oceanic Technology 17:525-531, http://dx.doi.org/10.1175/1520-0426(2000) 017<0525:ARTLSI>2.0.CO;2.

Xu, L., T. Rosmond, and R. Daley. 2005. Development of NAVDAS-AR: Formulation and initial tests of the linear problem. Tellus 57A:546-559, http://dx.doi.org/ 10.1111/j.1600-0870.2005.00123.x.

Zhao, Q., and F.H. Carr. 1997. A prognostic cloud scheme for operational NWP models. Monthly Weather Review 125:1,931-1,953, http://dx.doi.org/10.1175/1520-0493(1997) 125<1931:APCSFO>2.0.CO;2. 